OPEN ACCESS

Edited by:

Gilles Reverdin,

Centre National de la Recherche

Scientifique (CNRS), France

Reviewed by:

Folco Giomi

Independent Researcher, Padova, Italy

Pascal Lazure

Institut Français de Recherche pour

l'Exploitation de la Mer, France

*Correspondence:

Ricardo A. Scrosati

rscrosat@stfx.ca

Specialty section:

This article was submitted to

Ocean Observation,

a section of the journal

Frontiers in Marine Science

Received: 09 November 2021

Accepted: 27 December 2021

Published: 27 January 2022

Citation:

Scrosati RA (2022) Low Winter

Extremes in Intertidal Temperature in

Nova Scotia in the Absence of an Ice

Foot. Front. Mar. Sci. 8:811545.

doi: 10.3389/fmars.2021.811545

\section{Low Winter Extremes in Intertidal Temperature in Nova Scotia in the Absence of an Ice Foot}

\author{
Ricardo A. Scrosati* \\ Department of Biology, St. Francis Xavier University, Antigonish, NS, Canada
}

Keywords: ice foot, intertidal, sea ice, temperature, winter

\section{INTRODUCTION}

Intertidal environments are those occurring between the highest and lowest tide marks along marine shores and, thus, are found worldwide. Conditions for life differ markedly between high tides, when the intertidal zone is submerged, and low tides, when the intertidal zone is exposed to the air. Due to the exposure to aerial conditions, intertidal thermal extremes typically take place during low tides. Thus, particularly in seasonal climates, the highest values of intertidal temperature occur during summer low tides, while the lowest values occur during winter low tides (Lathlean et al., 2014; Stickle et al., 2016; Umanzor et al., 2017).

On coasts with cold winters, air temperature in winter is often negative and can cause physiological stress in intertidal organisms during low tides (Braby, 2007). However, when a stable layer of ice develops on the intertidal substrate (known as the ice foot; Barnes, 1999), the intertidal zone becomes insulated from extremes in air temperature even during low tides. This was shown, for instance, by a study done in eastern Canada. The Gulf of St. Lawrence is a large body of water located in this region. In winter, sea ice develops extensively across its surface (Saucier et al., 2003; Galbraith et al., 2018). On the Nova Scotia coast of this gulf, a stable ice foot has been demonstrated to cover intertidal habitats for weeks (Scrosati and Eckersley, 2007). In the winter of 2007 at a typical location on this coast (Sea Spray Shore; Figure 1), the average of daily minimum air temperature measured $2 \mathrm{~m}$ above the ground in a terrestrial environment near the intertidal zone was $-7.2^{\circ} \mathrm{C}$, while the lowest value was $-19.8^{\circ} \mathrm{C}$. However, intertidal temperature measured under the ice foot ranged only between $-2.4^{\circ} \mathrm{C}$ and $-1.1^{\circ} \mathrm{C}$ during the weeks when this cover of ice was stable (Scrosati and Eckersley, 2007).

About merely $100 \mathrm{~km}$ eastwards, on the open Atlantic coast of Nova Scotia (Figure 1), open coastal waters do not freeze in winter (Canadian Ice Service, 2021). This difference with the Gulf of St. Lawrence coast is remarkable because both coasts experience similarly cold winters (Environment Canada, 2021). The open Atlantic coast thus provides an opportunity to evaluate how the absence of an ice foot influences intertidal thermal extremes under these harsh winters. This article addresses this question using temperature data collected at a typical location on the open Atlantic coast of Nova Scotia.

\section{MATERIALS AND METHODS}

Temperature was quantified at Tor Bay Provincial Park $\left(45^{\circ} 11^{\prime} \mathrm{N}, 61^{\circ} 21^{\prime} \mathrm{W}\right)$, on the open Atlantic coast of Nova Scotia (Figure 1). On 30 November 2007, two submersible temperature loggers (StowAway TidbiT model, Onset Computer, Bourne, MA, USA) were attached to the rocky substrate at the middle intertidal zone (tidal amplitude is $1.8 \mathrm{~m}$ on this coast). Both loggers were attached to bedrock areas where macroalgal canopies were previously removed in a typical 


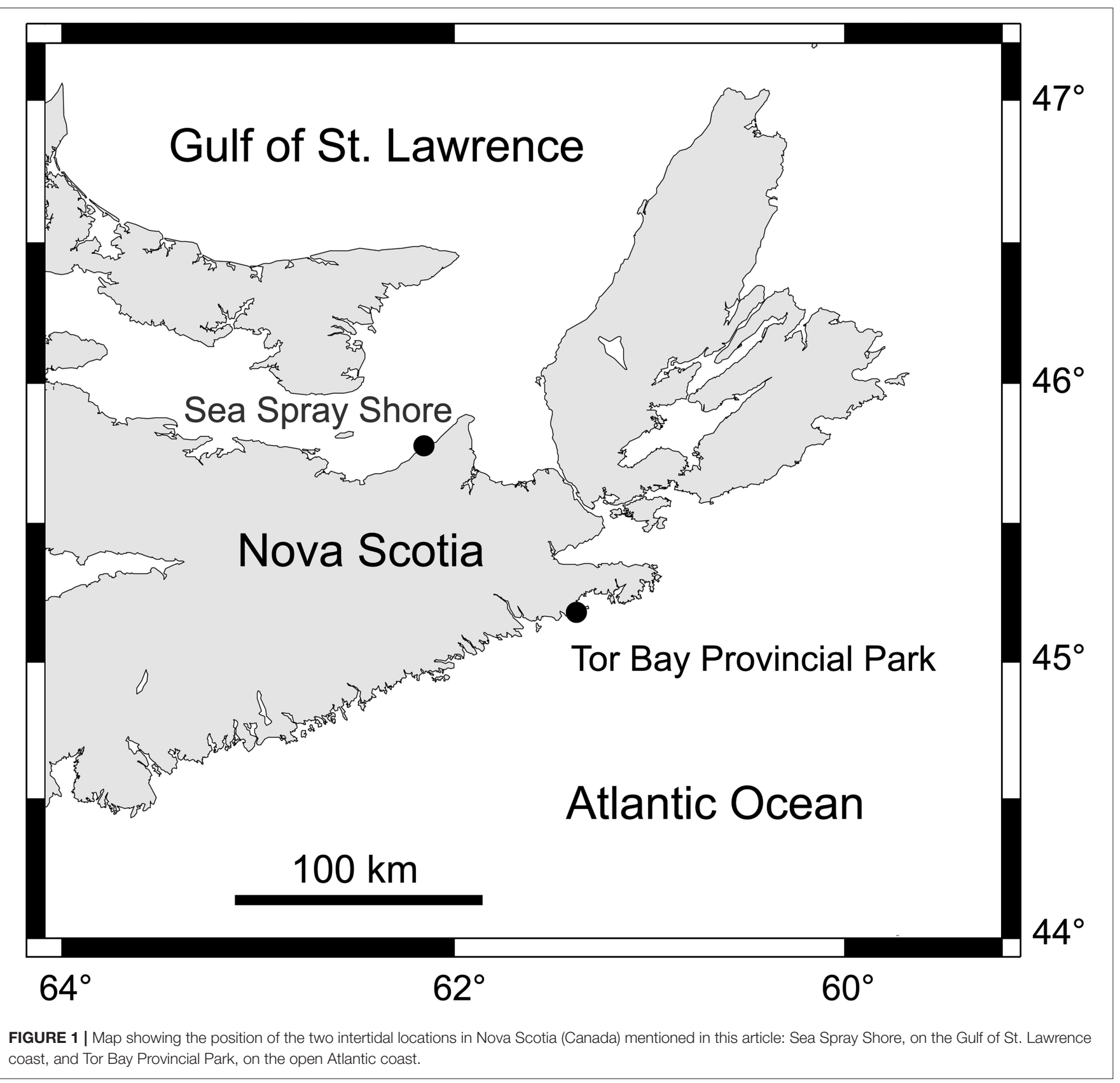

wave-sheltered habitat. In these intertidal environments, maximum water velocity (an indication of wave exposure) measured in-situ during high tides ranges between 3 and $6 \mathrm{~m}$ $s^{-1}$ (Scrosati and Heaven, 2007). In recent years, these sheltered environments have supported studies on intertidal ecology (Scrosati and Heaven, 2007; Scrosati et al., 2011; Scrosati and Freeman, 2019). Both loggers were permanently attached to the substrate using plastic cable ties secured to eye screws placed in holes drilled into the substrate, allowing almost no contact between the loggers and the substrate. These loggers took hourly measurements of intertidal temperature, thus spanning consecutive periods of high and low tides. As controls to document air temperature exclusively in terrestrial habitats, two other loggers were affixed at $2 \mathrm{~m}$ above the ground to tree branches that faced the ocean directly without obstructions and were $30 \mathrm{~m}$ away from the intertidal zone.

On 5 April 2008, the four loggers were collected. Unfortunately, one intertidal logger malfunctioned (its case was found cracked and there was seawater inside), so no data were available from that logger. However, the hourly temperature values were highly correlated between the two terrestrial loggers $(r=0.98, P<0.001, N=3,024)$, indicating the reliability of these loggers to properly measure temperature. Thus, the data retrieved from the surviving intertidal logger 
were deemed to be representative of intertidal conditions. From the data retrieved from this intertidal logger, the values of daily minimum intertidal temperature recorded between 1 December 2007 and 4 April 2008 were extracted. To show that the extreme negative values resulted from aerial exposure at low tide, the values of daily sea surface temperature (SST) were also extracted from this intertidal logger. Daily SST values were considered as the intertidal temperature recorded closest to the time of the highest tide of each day, when the intertidal logger was fully submerged. The time of such high tides was determined using information for the tide reference station that is closest to Tor Bay Provincial Park (Larry's River, $45^{\circ} 13^{\prime} \mathrm{N}, 61^{\circ} 23^{\prime} \mathrm{W}$; Tide and Current Predictor, 2021). To evaluate how daily temperature minima compared between intertidal and terrestrial conditions, the values of daily minimum temperature were also extracted from the two terrestrial loggers. The data on intertidal and terrestrial daily minimum temperature used for this article are freely available from the figshare online repository (Scrosati, 2021a). For completeness, the full sets of hourly temperature data measured at Tor Bay Provincial Park (this study) and at Sea Spray Shore (Scrosati and Eckersley, 2007) are also made freely available through the figshare online repository (Scrosati, 2021b).

\section{TEMPERATURE PATTERNS REVEALED BY THE DATA}

At the intertidal zone, daily minimum temperature was negative in 110 of the 126 days of the study (Figure 2A). The coldest period occurred during the second half of January, when intertidal temperature reached its lowest value for the season $\left(-14.1^{\circ} \mathrm{C}\right)$. In fact, the four lowest values of daily minimum intertidal temperature occurred during that period. For the entire study period, daily minimum intertidal temperature averaged $-4.2 \pm 0.3^{\circ} \mathrm{C}($ mean $\pm \mathrm{SE}, N=126)$. Overall, the intertidal

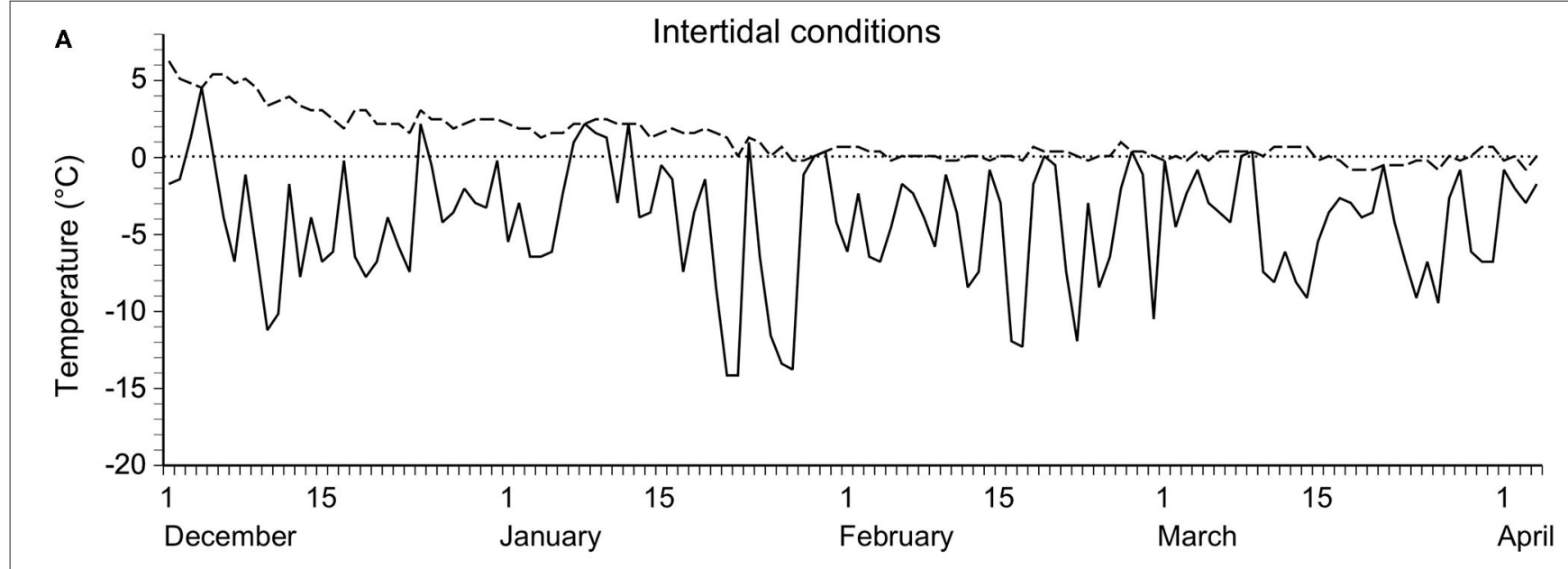

B

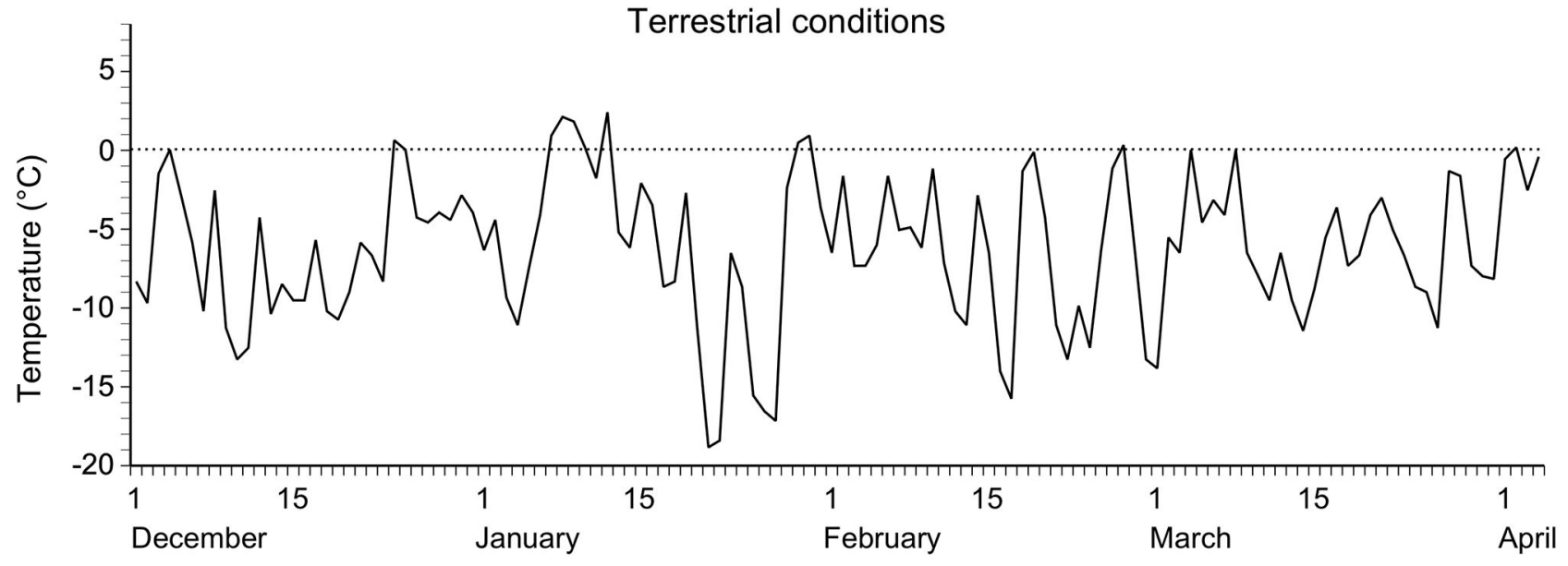

FIGURE 2 | (A) Daily minimum intertidal temperature (solid line) and daily sea surface temperature (dashed line) and (B) daily minimum temperature (means of two loggers) in a nearby terrestrial environment between 1 December 2007 and 4 April 2008 at Tor Bay Provincial Park, on the open Atlantic coast of Nova Scotia, Canada. 
zone experienced 11 days with temperatures lower than $-10^{\circ} \mathrm{C}$, 50 days with temperatures lower than $-5^{\circ} \mathrm{C}$, and 99 days with temperatures lower than the lowest SST value recorded for the season $\left(-0.8^{\circ} \mathrm{C}\right)$.

To summarize temperature patterns on land, the values of daily minimum temperature from the two terrestrial loggers were averaged for each day, given how highly their hourly values were correlated. Based on these daily means, daily minimum temperature at the nearby terrestrial environment was negative in 112 of the 126 days of the study (Figure 2B). The coldest period also occurred during the second half of January, when air temperature reached its lowest absolute value for the season $\left(-19.1^{\circ} \mathrm{C}\right)$. For the entire study period, daily minimum temperature in the terrestrial environment averaged $-6.2 \pm$ $0.4^{\circ} \mathrm{C}$ (mean $\pm \mathrm{SE}, N=126$ ), which was lower than for the intertidal environment (paired $t$-test, $t=9.9, P<0.001$ ). Overall, however, daily temperature minima were temporally correlated between the intertidal and terrestrial environments $(r=0.88, P$ $<0.001, N=126)$.

The hourly values of intertidal temperature and the hourly values of terrestrial temperature (hourly means between both terrestrial loggers) were also temporally correlated, although more weakly $(r=0.51, P<0.001, N=3,024)$ because of the decoupling of values between both environments during high tides.

\section{DISCUSSION AND ECOLOGICAL IMPLICATIONS}

The comparison of daily temperature minima in terrestrial environments between the Gulf of St. Lawrence coast (Scrosati and Eckersley, 2007) and the open Atlantic coast (this study) of Nova Scotia confirms the known similarity in climatic winter conditions across this region (Environment Canada, 2021). Therefore, the present article shows that, under the harsh conditions that characterize eastern Canadian winters, the absence of an ice foot subjects intertidal environments to markedly negative temperatures that closely follow daily changes in air temperature minima. While low, however, these daily intertidal extremes are not always as low as in nearby terrestrial environments, likely as a result of the moderating effects of high tides, as SST is typically higher than air temperature during the winter.

A recent study (Scrosati et al., 2020) provides additional measures of intertidal temperature for the Nova Scotia coast, although there are two relevant differences relative to this study. On the one hand, that study measured temperature in wave-exposed intertidal habitats, which are known to differ in thermal properties from wave-sheltered habitats (where the present study was done) because of wave splash. On the other hand, the main objective of the present study can be addressed thanks to the availability of temperature data measured simultaneously in intertidal and nearby terrestrial habitats, which the above study did not do because it was driven by different objectives.

The ecological implications of these findings are important. Intertidal algae and invertebrates from cold-temperate shores are adapted to surviving negative temperatures (Collén and Davison, 1999; Waller et al., 2006; Storey et al., 2013; Rothäusler et al., 2016). However, mortality occurs when temperature falls below certain thresholds. For example, winter lethal temperatures typically range between $-10^{\circ} \mathrm{C}$ and $-15^{\circ} \mathrm{C}$ for these organisms (Crisp and Ritz, 1967; Williams, 1970; Bourget, 1983; Davison et al., 1989; Loomis, 1995; Collén and Davison, 1999; Ansart and Vernon, 2003; Davenport and Davenport, 2005; Stickle et al., 2015; Chiba et al., 2016). Thus, in the absence of an ice foot, intertidal organisms might often experience lethal thermal levels in winter. Even the repeated exposure to sublethal thermal levels may still cause mortality (Roland and Ring, 1977; Murphy and Johnson, 1980; Bourget, 1983; Dudgeon et al., 1990). These considerations may lead to counterintuitive predictions in light of the ongoing global warming (Intergovernmental Panel on Climate Change, 2021). On coasts that currently develop a winter ice foot, the progressive disappearance of winter sea ice due to climate warming will actually expose intertidal organisms to markedly negative air temperatures in winter. Thus, the resulting cold stress might cause widespread mortality at least until thermal adaptation can take place after the permanent loss of a winter ice foot.

\section{DATA AVAILABILITY STATEMENT}

The data on daily minimum temperature and daily sea surface temperature for Tor Bay Provincial Park are freely available from the figshare online repository (https://doi.org/10.6084/m9. figshare.17297348.v1); the data on hourly temperature for Tor Bay Provincial Park and Sea Spray Shore are also available from the figshare online repository (https://doi.org/10.6084/m9. figshare.17297771.v1).

\section{AUTHOR CONTRIBUTIONS}

The author confirms being the sole contributor of this work and has approved it for publication.

\section{FUNDING}

This study was funded by a Discovery Grant (number 311624) from the Natural Sciences and Engineering Research Council of Canada (NSERC), by a grant (number 210283) from the Canada Research Chairs program (CRC), and by a Leaders Opportunity Grant (number 202034) from the Canada Foundation for Innovation (CFI) awarded to RS.

\section{ACKNOWLEDGMENTS}

I am grateful to the two reviewers for their constructive comments. 


\section{REFERENCES}

Ansart, A., and Vernon, P. (2003). Cold hardiness in molluscs. Acta Oecol. 24, 95-102. doi: 10.1016/S1146-609X(03)00045-6

Barnes, D. K. A. (1999). The influence of ice on polar nearshore benthos. J. Mar. Biol. Assoc. U. K. 79, 401-407. doi: 10.1017/S0025315498000514

Bourget, E. (1983). Seasonal variations of cold tolerance in intertidal mollusks and relation to environmental conditions in the St. Lawrence Estuary. Can. J. Zool. 61, 1193-1201. doi: 10.1139/z83-162

Braby, C. E. (2007). "Cold stress" in Encyclopedia of Tidepools and Rocky Shores, eds. M. W. Denny and S. D. Gaines (Berkeley, CA: University of California Press), 148-150.

Canadian Ice Service (2021). Available online at: http://ice-glaces.ec.gc.ca (accessed November 8, 2021).

Chiba, S., Iida, T., Tomioka, A., Azuma, N., Kurihara, T., and Tanaka, K. (2016). Population divergence in cold tolerance of the intertidal gastropod Littorina brevicula explained by habitat-specific lowest air temperature. J. Exp. Mar. Biol. Ecol. 481, 49-56. doi: 10.1016/j.jembe.2016.04.009

Collén, J., and Davison, I. R. (1999). Reactive oxygen production and damage in intertidal Fucus spp. (Phaeophyceae). J. Phycol. 35, 54-61. doi: 10.1046/j.1529-8817.1999.3510054.x

Crisp, D. J., and Ritz, D. A. (1967). Changes in temperature tolerance of Balanus balanoides during its life cycle. Helgoländ. Meeresunt. 15, 98-115. doi: $10.1007 / \mathrm{BF} 01618612$

Davenport, J., and Davenport, J. L. (2005). Effects of shore height, wave exposure, and geographical distance on thermal niche width of intertidal fauna. Mar. Ecol. Prog. Ser. 292, 41-50. doi: 10.3354/meps292041

Davison, I. R., Dudgeon, S. R., and Ruan, H. M. (1989). Effect of freezing on seaweed photosynthesis. Mar. Ecol. Prog. Ser. 58, 123-131. doi: 10.3354/meps058123

Dudgeon, S. R., Davison, I. R., and Vadas, R. L. (1990). Freezing tolerance in the intertidal red algae Chondrus crispus and Mastocarpus stellatus: relative importance of acclimation and adaptation. Mar. Biol. 106, 427-436. doi: $10.1007 / \mathrm{BF} 01344323$

Environment Canada (2021). Weather, Climate, and Hazard. Available online at: http://climate.weather.gc.ca (accessed November 8, 2021).

Galbraith, P. S., Chassé, J., Caverhill, C., Nicot, P., Gilbert, D., Lefaivre, D., et al. (2018). Physical Oceanographic Conditions in the Gulf of St. Lawrence during 2017. Fisheries and Oceans Canada, Canadian Science Advisory Secretariat Research Document 2018/050. Available online at: http://www.dfo-mpo.gc.ca/ csas-sccs/Publications/ResDocs-DocRech/2018/2018_050-eng.html (accessed November 8, 2021).

Intergovernmental Panel on Climate Change (2021). Climate Change 2021: The physical Science Basis. Available online at: https://www.ipcc.ch/report/ar6/wg1/ downloads/report/IPCC_AR6_WGI_Full_Report.pdf (accessed November 8, 2021).

Lathlean, J. A., Ayre, D. J., and Minchinton, T. E. (2014). Estimating latitudinal variability in extreme heat stress on rocky intertidal shores. J. Biogeogr. 41, 1478-1491. doi: 10.1111/jbi.12311

Loomis, S. H. (1995). Freezing tolerance of marine invertebrates. Oceanogr. Mar. Biol. 33, 337-350.

Murphy, D. J., and Johnson, L. C. (1980). Physical and temporal factors influencing the freezing tolerance of the marine snail Littorina littorea (L.). Biol. Bull. 158, 220-232. doi: 10.2307/1540932

Roland, W., and Ring, R. A. (1977). Cold, freezing, and desiccation tolerance of the limpet Acmaea digitalis (Eschscholtz). Cryobiology 14, 228-235. doi: 10.1016/0011-2240(77)90143-2

Rothäusler, E., Sjöroos, J., Heye, K., and Jormalainen, V. (2016). Genetic variation in photosynthetic performance and tolerance to osmotic stress (desiccation, freezing, hyposalinity) in the rocky littoral foundation species Fucus vesiculosus (Fucales, Phaeophyceae). J. Phycol. 52, 877-887. doi: 10.1111/jpy.12455

Saucier, F. J., Roy, F., Gilbert, D., Pellerin, P., and Ritchie, H. (2003). Modeling the formation and circulation processes of water masses and sea ice in the Gulf of St. Lawrence, Canada. J. Geophys. Res. 108, 3269. doi: 10.1029/2000JC000686
Scrosati, R., and Eckersley, L. K. (2007). Thermal insulation of the intertidal zone by the ice foot. J. Sea Res. 58, 331-334. doi: 10.1016/j.seares.2007.08.003

Scrosati, R., and Heaven, C. (2007). Spatial trends in community richness, diversity, and evenness across rocky intertidal environmental stress gradients in eastern Canada. Mar. Ecol. Prog. Ser. 342, 1-14. doi: 10.3354/meps342001

Scrosati, R. A. (2021a). Data on Intertidal and Terrestrial Temperature in Winter for Tor Bay Provincial Park. Figshare Dataset. Available online at: https://doi. org/10.6084/m9.figshare.17297348.v1 (accessed December 20, 2021).

Scrosati, R. A. (2021b). Data on Hourly Temperature in Winter at Sea Spray Shore and Tor Bay Provincial Park. Figshare Dataset. Available online at: https://doi. org/10.6084/m9.figshare.17297771.v1 (accessed December 20, 2021).

Scrosati, R. A., Ellrich, J. A., and Freeman, M. J. (2020). Half-hourly changes in intertidal temperature at nine wave-exposed locations along the Atlantic Canadian coast: a 5.5-year study. Earth Syst. Sci. Data 12, 2695-2703. doi: 10.5194/essd-12-2695-2020

Scrosati, R. A., and Freeman, M. J. (2019). Density of intertidal barnacles along their full elevational range of distribution conforms to the abundant-centre hypothesis. PeerJ 7, e6719. doi: 10.7717/peerj.6719

Scrosati, R. A., van Genne, B., Heaven, C. S., and Watt, C. A. (2011). Species richness and diversity in different functional groups across environmental stress gradients: a model for marine rocky shores. Ecography 34, 151-161. doi: 10.1111/j.1600-0587.2010.06119.x

Stickle, W. B., Lindeberg, M., and Rice, S. D. (2015). Comparative freeze tolerance and physiological adaptations of three species of vertically distributed rocky intertidal gastropods from southeast Alaska. J. Exp. Mar. Biol. Ecol. 463, 17-21. doi: 10.1016/j.jembe.2014.10.027

Stickle, W. B., Lindeberg, M., Rice, S. D., Munley, K., and Reed, V. (2016). Seasonal changes in the thermal regime and gastropod tolerance to temperature and desiccation stress in the rocky intertidal zone in southeast Alaska. J. Exp. Mar. Biol. Ecol. 482, 56-63. doi: 10.1016/j.jembe.2016.04.011

Storey, K. B., Lant, B., Anozie, O. O., and Storey, J. M. (2013). Metabolic mechanisms for anoxia tolerance and freezing survival in the intertidal gastropod Littorina littorea. Comp. Biochem. Physiol. A 165, 448-459. doi: 10.1016/j.cbpa.2013.03.009

Tide and Current Predictor (2021). Larry's River, Nova Scotia. Available online at: http://tide.arthroinfo.org/tideshow.cgi?site=Larry\%27s+River\%2C+Nova+ Scotia (accessed November 8, 2021).

Umanzor, S., Ladah, L., Calderón-Aguilera, L. E., and Zertuche-González, J. A. (2017). Intertidal macroalgae influence macroinvertebrate distribution across stress scenarios. Mar. Ecol. Prog. Ser. 584, 67-77. doi: 10.3354/meps12355

Waller, C. L., Worland, M. R., Convey, P., and Barnes, D. K. A. (2006). Ecophysiological strategies of Antarctic intertidal invertebrates faced with freezing stress. Polar Biol. 29, 1077-1083. doi: 10.1007/s00300-006-0152-3

Williams, R. J. (1970). Freezing tolerance in Mytilus edulis. Comp. Biochem. Physiol. 35, 145-161. doi: 10.1016/0010-406X(70)90918-7

Conflict of Interest: The author declares that the research was conducted in the absence of any commercial or financial relationships that could be construed as a potential conflict of interest.

Publisher's Note: All claims expressed in this article are solely those of the authors and do not necessarily represent those of their affiliated organizations, or those of the publisher, the editors and the reviewers. Any product that may be evaluated in this article, or claim that may be made by its manufacturer, is not guaranteed or endorsed by the publisher.

Copyright (c) 2022 Scrosati. This is an open-access article distributed under the terms of the Creative Commons Attribution License (CC BY). The use, distribution or reproduction in other forums is permitted, provided the original author(s) and the copyright owner(s) are credited and that the original publication in this journal is cited, in accordance with accepted academic practice. No use, distribution or reproduction is permitted which does not comply with these terms. 